0147-1767(94)E0001-D

\title{
ACHIEVEMENT GOALS: A SITUATIONAL-CONTEXTUAL ANALYSIS
}

\author{
REKHA SINGHAL \\ Indian Institute of Forest Management
}

\section{GIRISHWAR MISRA}

\section{University of Delhi}

\begin{abstract}
Recent studies have indicated that the generalizability of traditional theory of achievement motivation across cultures is considerably limited. Empirical evidence from various cultures points out that there are cross-cultural differences in the meaning of achievement that play a crucial role in determining the achievement efforts of the people in respective cultures. The present study is a step towards delineating more fully the role of meaning in directing achievement behavior across different groups within the Indian cultural context. It investigated the effects of perceived sense of self and perceived expectations of on the preferences for achievement goals in individualistic, familial, and societal spheres among male and female adolescents and young adults. The results indicated that the expectations held by the significant others (e.g., parents, teachers, peers) and age level were the most powerful determinants of the perceived importance of achievement goals. In addition, gender, age, and sense of self evinced joint influences on the preferences for certain achievement goals. The findings are discussed in the light of a situational-contextual model of achievement motivation, and implications for understanding and managing motivation in multicultural perspective are indicated.
\end{abstract}

In recent years, increasingly greater attention has been paid to empirically study the determinants and consequences of achievement-related cognitions (Cooper, 1983; Misra, 1985; Nicholls, 1984; Weiner, 1986). The theoretical explanations of achievement expressed through these congitions strivings range between personality-based individualistic ex-

Girishwar Misra is currently an Indo-U.S. Fulbright Fellow, School of Education, University of Michigan, Ann Arbor.

Reprint requests should be sent to Rekha Singhal, Indian Institute of Forest Management, Nehru Nagar, P. B. 357, Bhopal-462003, India. 
planations (McClelland, 1961) and sociocultural explanations (Maehr, $1974,1984)$. The psychological studies in this field have generally been narrow in their focus on achievement tasks and have concentrated on a set of selected measures and a limited range of variables. For instance, the studies on achievement motive utilizing assessment devices like Thematic Apperception Test, sentence completion test, and various psychometric measures often try to assess the strength of achievement motive as an enduring personality disposition using the same scale for different cultural and subcultural groups. However, many studies even in this tradition have yielded notable differences in the strength of achievement motive owing to a wide variety of individual and social factors such as social class, age, and social disadvantage (e.g., Mehta \& Mohta, 1974; Melikian, Ginsberg, Cuceloglu, \& Lynn, 1971; Tiwari \& Misra, 1977).

A second line of research that provides the framework for present study concerns the differences in the construal of achievement strivings. This approach emphasizes the role of cultural meaning systems implicating diverse achievement strivings and suggesting that the differences in achievement scores on various measures may reflect differences in the various ways of construing achievement. As Maehr pointed out: (1974)

Achicvement is a function of more or less ephemeral social expectations that are embodied in what we call norms. In a very real sense, a social group tells a person what to strive for as well as how to attain this end. The effect of such norms is clearly an important variable in any achieving situation. (p. 66)

In subsequent research, several investigators have found important qualitative differences in the construal of achievement across different groups and cultures (e.g., Chen \& Uttal, 1988; Fyans, Salili, Maehr, \& Desai, 1983; Kukla \& Scher, 1986; Maehr \& Nicholls, 1980). Gallimore (1974) questioned the transferability of McClelland's model to the Hawaiian Americans where affiliation is the central theme of life. He reported a significant positive relationship between actual school achievement and affiliation while achievement need remained uncorrelated. Similar results have been observed in Japanese (DeVos, 1973; Doi, 1982), Mexican Americans (Ramirez \& Price-Williams, 1976), and a Navajo group of Native Americans (Duda, 1980). However, in attempts to understand the intercultural differences, a wide range of intracultural variations are usually ignored. Recent research on achievement cognitions indicate that the meaning of achievement not only differs by culture but also by age, gender, social class, and the type of context in which achievement is assessed (Ewing, 1981; Maehr \& Nicholls, 1980; Miller, 1984).

Against this background, the present study investigated the range and type of preferences for achievement goals among Indian adolescents and 
young adults within the framework of Maehr's $(1978,1984)$ situationalcontextual model of achievement. This model assumes that variation in achievement activity is primarily a function of three factors (i.e., expectations, goals, and self). As in the case of most behaviors, in achievement too, people respond to the norms, values, and perceived expectations of the groups that are significant in their experiential world. In the context of present study, the expectations on the part of teachers, parents, and peers were considered crucial in determining the meaning of achievement. The second component of the model (i.e., goal) was considered in terms of different types of goals sought by the people. In the present study, three types of goals (i.e., individual, familial, and societal) were taken into account. The third component of the model is the sense of self that interacts with other variables to determine the meaning of achievement. Finally, the personal characteristics such as age and sex are also assumed to play a significant role in the shaping of achievement cognitions. Different societies vary in prescribing the norms and standards in relation to age and sex. Within most societies there exist clearly articulated differential role expectations for males and females associated with various developmental stages.

In particular, this study aimed at determining variations in the construals of achievement goals in relation to age, gender, sense of self, and expectations of significant others. The Indian sociocultural context emphasizes a holistic-organic view (Shweder \& Bourne, 1984) in which a person and his or her identify is a socially constituted part of the universal order. He or she, therefore, is embedded in the collectivity in a significant manner (Tripathi, 1988). The maintenance of social relationship with others, dependence, and shared responsibilities are found to be important features characterizing Indian upbringing (Kakar, 1978; Seymour, 1988). The symbiotic relationship between the child and parents observed in Indian setting stresses more on conformity and interdependence than autonomy and independence. This pattern of socialization shows marked gender differences. Traditionally, girls are required to develop proficiency in day-to-day family management and in the sharing of household responsibilities, whereas boys are trained to acquire professional skills with an aim to money and to support the family (Uplaonkar, 1983). As Anandlakshmy (1975) noted, the sex roles are clearly differentiated and influence socialization from birth onwards. The children grow in hierarchically structured overlapping social groups and collectives (e.g., extended family, kinship network, caste groups) that shape their personalities, values, and conduct in unique ways (J. B. P. Sinha, 1982). However, with the overwhelming spread of Western education, increased technological sophistication, improved communication, and influence of media the traditional sex-role differences are changing, and in recent years a stage of transition is clearly visible. Shifts 
from joint families (towards liberal extended and nuclear families), independence-oriented childrearing practices, and emphasis on modernity are observed (Nandy, 1982; D. Sinha, 1988).

Although our previous studies on achievement cognitions (Misra \& Agarwal, 1985; and Agarwal \& Misra 1986) have found evidence about achievement goals, means in Indian young adult samples predominantly reflect a strong social concern rather than individualistic striving and competition. Extending our previous work, the present study intends to examine the role of developmental stage, gender, and expectations of significant others in determining the perceived importance of individual, familial, and societal goals. In view of the situational-contextual model of achievement outlined earlier and the features of Indian sociocultural tradition indicated before, it was contended that the perceived importance of achievement goals would evince significant effects of developmental stage, gender, sense of self, and perceived expectations of significant others. In particular, significant interactions of developmental stage with gender and sense of self were predicted. In the light of qualitatively different role demands across adolescence and early adulthood, it was expected that the perceived importance of achievement goals would evince differential influences of sense of self among males and females from adolescence and young adulthood stages.

\section{METHOD}

\section{Participants}

Eighty students ( 40 boys, 40 girls) enrolled in 10th and undergraduate courses in a college in Allahabad in North India participated in the study. These educational levels were employed with the purpose of having representation of adolescent and early adulthood stages of development. The means of their age values were 15 years $(S D=1.76)$ and 19.5 years $(S D=.96)$, respectively. They were drawn from an initial large sample $(N=300)$ that took the measure of sense of self.

\section{Measures}

Sense of Self. An abridged version of Fleming and Courtney's (1984) Self Rating Scale was used to assess the sense of self. The original measure consists of 36 items pertaining to self-regard, social confidence, school abilities, physical appearance, and physical abilities. In the present study, a shortened Hindi version consisting of 25 items was used. These items were selected on the basis of a pilot study $(n=30)$ on a sample similar to the one used in the main study. The retest reliability of 
this measure was .68 , and the alpha coefficient was .89 for this measure. The responses had to be given on 6-point scales. To avoid response bias, some items were negatively cued and the order of scoring was reversed. For instance, the item "How often do you feel inferior to most of the people you know?" was rated on a scale ranging from never (1) to always (6). The possible score on this measure ranged between 25 and 150 .

Achievement Goals. The measure of achievement goals consisted of a set of 32 goals derived from previous studies (Misra \& Agarwal, 1985). They dealt with three main spheres (i.e., the individual, the family, and the society). The domain of individual level goals consisted of concerns about basic needs (materialistic), quality of life (positive experience), concern with the welfare of other members of society (prosocial), and career planning. The familial goals were concerned with maintaining relationship with family members. The societal goals were associated with the development of society. In total, the following six goal subscales were conceptually formed.

1. Materialistic goals: It had five items such as "to earn money," "to gratify basic needs," and "to manage objects of life comforts."

2. Positive experiences: It had six goals such as "to lead a happy life," "to be independent," and "to travel and wander."

3. Prosocial goals: It included five goals such as "desire for well-being of others," "to help others," and "to be a good person."

4. Career planning: It had seven goals including "to gain knowledge," "to get a job," "success in sports," and "to be adept in household and cultural work."

5. Familial goals: This subscale had four items such as "siblings' progress" and "to respect and serve elders and other family members."

6. Societal goals: It had five items such as "agricultural progress," "to serve society and country," and "progress of village."

The subject's task was to rate the importance of each achievement goal separately on a 4-point rating scale ranging from unimportant (1) to very much important (4). The 1-month retest reliability of the measure has been estimated at .87 .

\section{Design}

The study involved a $2 \times 2 \times 2 \times 4$ factorial mixed-model design with two developmental levels (adolescence/early adulthood), two gender groups (male/female), two levels of sense of self (low/high) as between-group factors, and four types of perceived expectations (self/ 
peer/teachers/parents) as a within-group factor. There were 10 participants in each of the between-factor cells of the design.

\section{Procedure}

The study consisted of two phases. In the first phase, the measure of sense of self was administered on the large sample in small group settings. The distribution of total scores on this measure was obtained and Q1 and Q3 were determined. Using these scores as criteria, the low and high sense of self of participants were identified. In the second phase of the study, these participants were individually asked to rate the importance of each of the 32 achievement goals under four conditions (i.e., self, parental expectation, teacher expectation, and peer expectation). The participants were asked to imagine the stance taken by these significant others toward delineating achievement goals for their wards. The order of presentation of goals was varied across the four expectation conditions. Also, the order of the four expectation conditions was varied across participants.

\section{RESULTS}

The total scores obtained by each participant on the six goal subscales were subjected to separate $2 \times 2 \times 2 \times 4$ mixed factorial analyses of variance. The analyses yielded several significant main and interaction effects.

\section{Main Effects}

The mean scores as functions of the main effects of sense of self, gender, age, and type of expectation are shown in Table 1. The mean importance ratings indicate that the effect of sense of self was significant for the individual level goal of positive experiences. The high-sense-ofself participants viewed positive experiences significantly more important than their low-sense-of-self counterparts. In regard to other goals, the high-and low-sense-of-self groups shared a common pattern. The main effect of gender was significant for the individual-level goal of career planning. The female participants displayed greater preference for this goal than their male participants. The age-related differences were significant for five goals. It was found that adolescents perceived the materialistic, prosocial, career-planning, familial, and societal goals more important than their young adult counterparts. The goal of positive experiences was equally shared by both of them.

Finally, the main effect of perceived expectation emerged to be significant for all of the goals except career planning, which was viewed as equally important under all of the four expectation conditions. The inter- 


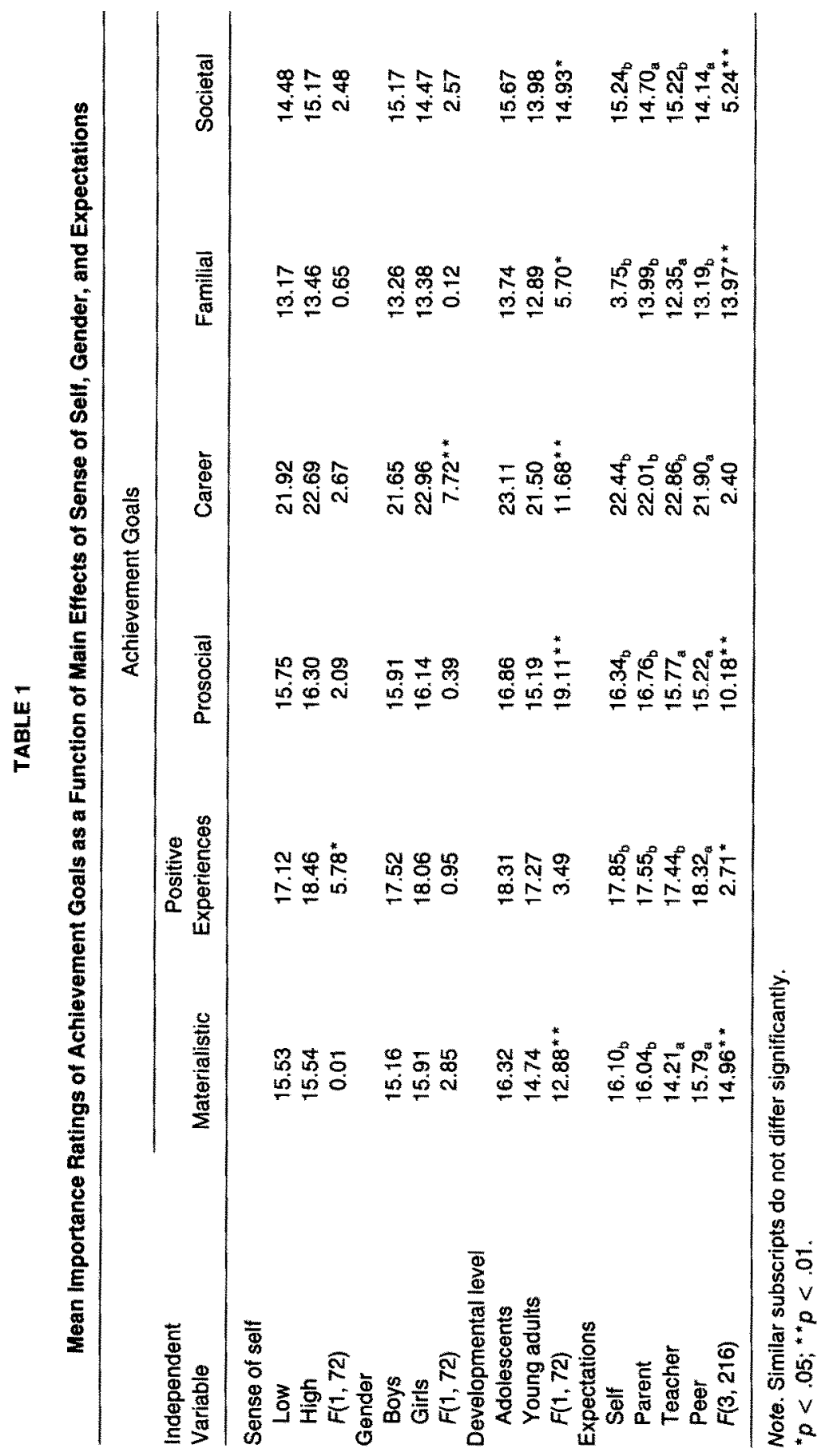


nal mean comparison revealed that the materialistic and prosocial goals were rated less important under teacher and peer expectation conditions than under self and parental expectation conditions. The goal of positive experiences was viewed as more important under peer expectation than under self, parental, and teacher expectation conditions. The familial goal was considered more important under self, peer, and parental expectation conditions than under the teacher expectation condition. The societal goal was perceived as more important under the self and teacher expectation conditions than under the parental and peer expectation conditions. A close perusal of the mean scores revealed that the perceived importance of goals under the self-expectation condition was very close to those noted under the parental expectation condition. In contrast, the importance of the ratings of goals under the peer expectation condition were usually different from other expectation conditions.

\section{Interaction Effects}

Turning to the interaction effects, the analyses revealed three 2-way significant Gender $\times$ Developmental Level interactions for materialistic, familial, and societal goals. Table 2 reports the cell means for these interactions. It was observed that the male participants gave equal weights to these goals across both the age levels. In contrast, the adolescent females viewed these goals more important than females of the young adult group. In general, the gender differences were minimal at the older age level for materialistic and familial goals, whereas the societal goals evinced an opposite trend.

A significant Gender $\times$ Expectation interaction was noted for the goal of positive experiences, $F(3,216)=3.45, p<.05$. It was found that the female participants considered it more important under the parental, teacher, and peer expectation conditions $(M=18.00,17.80$, 18.97, respectively) than did the male participants $(M=17.10,17.07$, 17.69 , respectively). However, under the self-expectation condition, the male participants viewed this goal more as important $(M=18.22)$ than did the female participants $(M=17.42)$.

The analysis also indicated significant two-way Developmental Level $\times$ Expectations interactions for four subgoals (i.e., positive experiences, prosocial, familial, and societal). Table 3 presents the mean scores for these interactions. It is clear that the adolescents had a relatively more favorable perception of these goals than did the young adults. They viewed these goals similarly under teacher and peer expectation conditions. The two age groups, however, perceived positive experiences as well as familial and societal goals. Similarly, under the self-expectation condition, the importance of ratings for the prosocial and familial goals under the parental expectation condition were similar for these groups. 


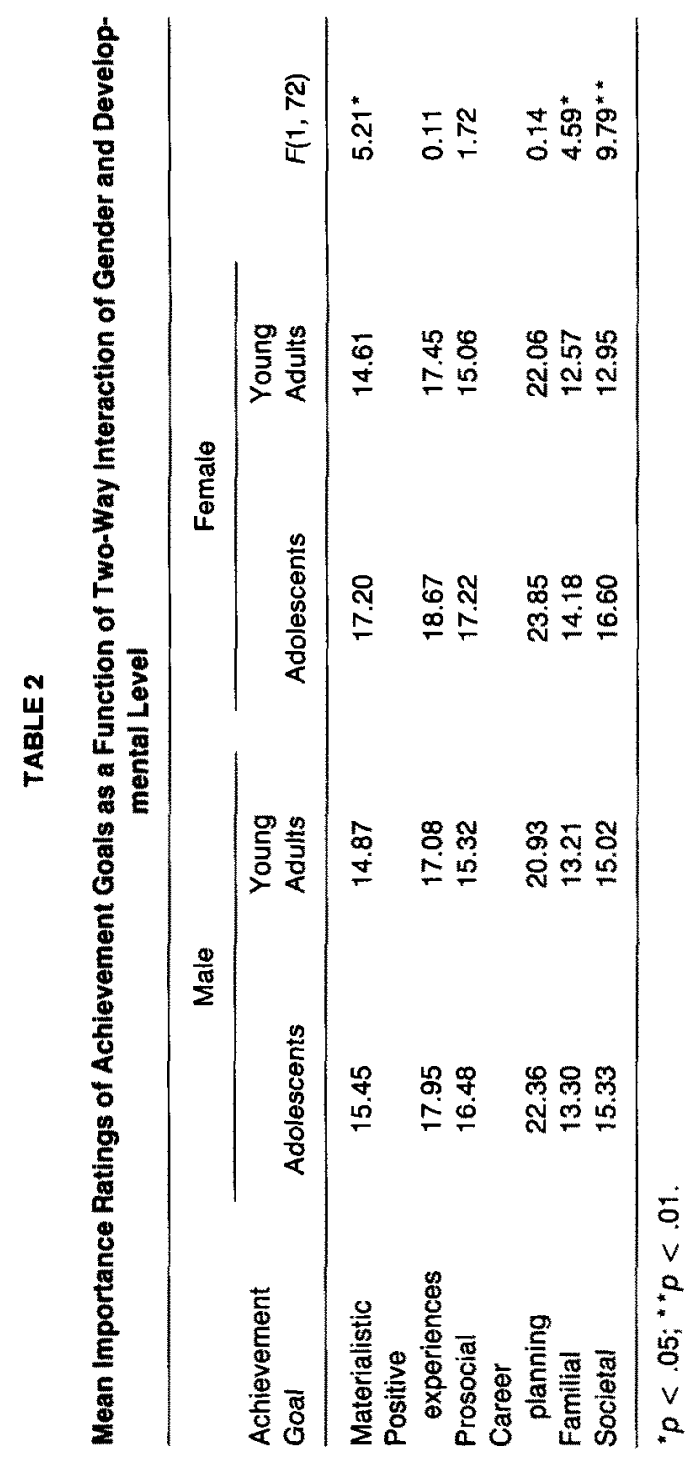




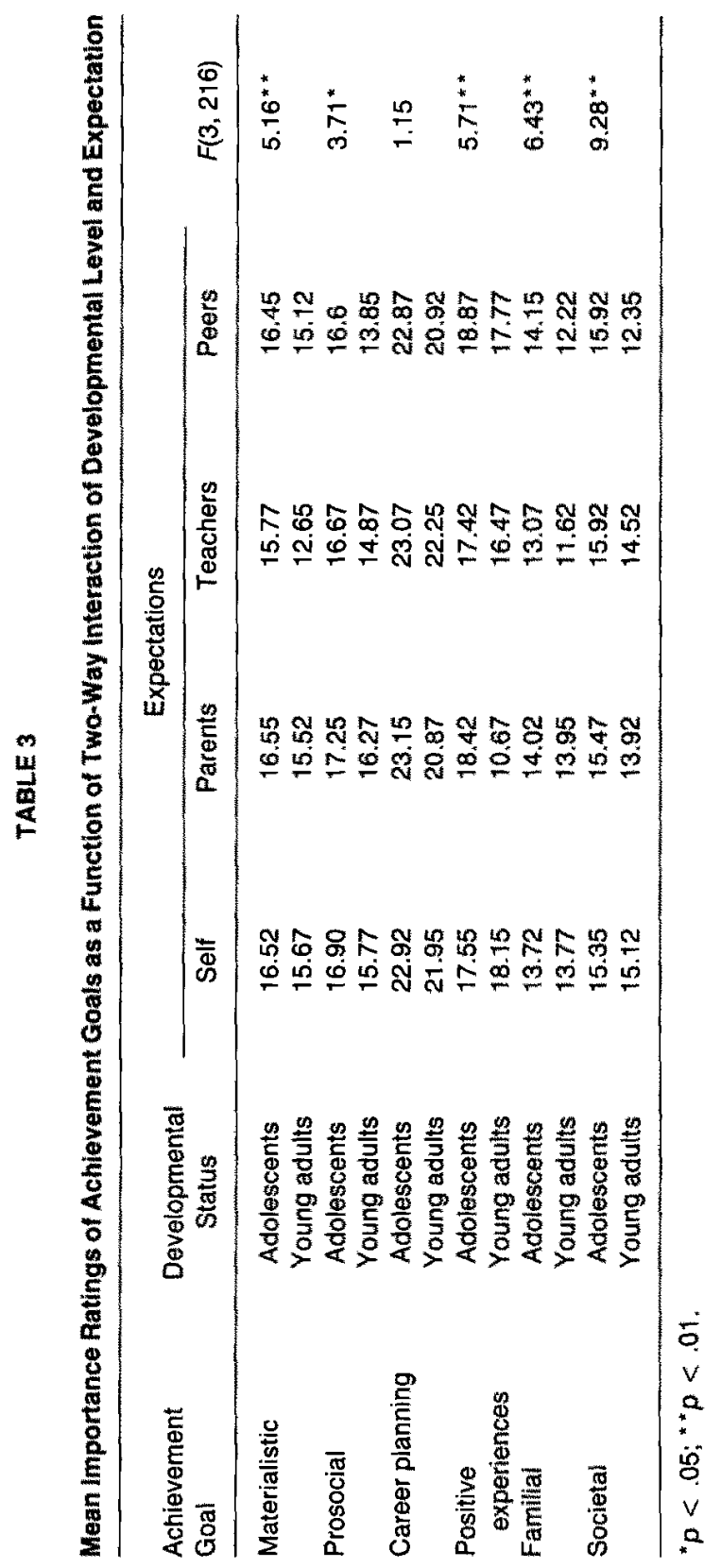


Finally, the adolescents' perceptions under the self-expectation condition were very similar to those noted under the expectations reflecting significant others.

A significant three-way Gender $\times$ Developmental Level $\times$ Expectation interaction, $F(3,216)=4.33, p<.01$, was found for the category of familial goals. Figure 1 shows that the female participants considered familial goals more important than did males at the younger age level under the teacher and peer expectation conditions. In contrast, the opposite was true for males, who perceived it more important than did females during early adulthood. In general, the younger females and older males viewed familial goals as more important under the teacher and peer expectation conditions than did their respective counterparts. It appears that this interaction is mainly due to age-related differences in the perceived importance of goals among female participants under different cxpectation conditions.

The three-way Sense of Self $\times$ Gender $\times$ Developmental Level interaction was significant for prosocial goals, $F(1,72)=3.72, p<.05$, and career planning, $F(1,72)=8.48, p<.01$. The shape of curves representing the interaction for the prosocial goal (Figure 2 ) indicates that the high-sense-of-self males had equal preference across both the age levels, whereas their low-sense-of-self counterparts evinced decrement in the preference ratings with advancing age.

In the case of females, high sense of self was associated with more positive perception of these goals at the younger age level. Figure 3 reveals a similar pattern, with the one noticeable difference being that the low-sense-of-self female participants viewed the goal similarly across both the age levels. Thus, the effect of sense of self on the perception of goals in the younger and older participants varied in the male and female participants. Other three-way and four-way interactions could not reach the significance level.

\section{DISCUSSION}

The present results demonstrate that the preferences for achievement goals were related not only to individuals' sense of self and gender but also, and even more importantly, to the perceived expectations held by the significant others and developmental level. It, therefore, seems reasonable to assert that both personal and situational factors jointly determine the preferences for achievement goals.

A close perusal of the findings reveals that the expectations of significant others was a significant factor contributing to the goal preferences displayed by the present Indian sample. Also, it was noted that the effect of perceived expectations varied for the different types of goals. The results showed that parental expectation yielded greater importance rat- 


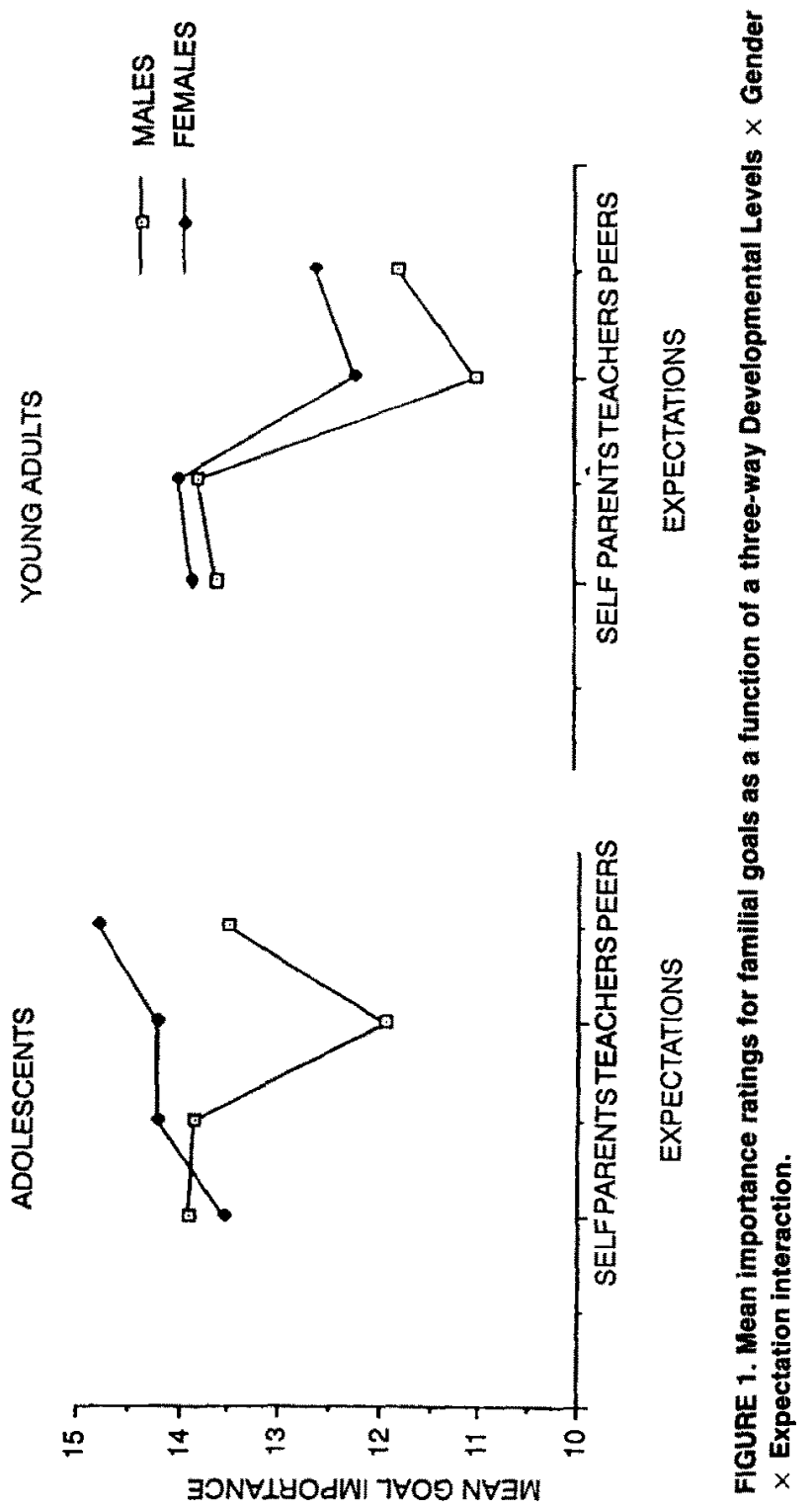




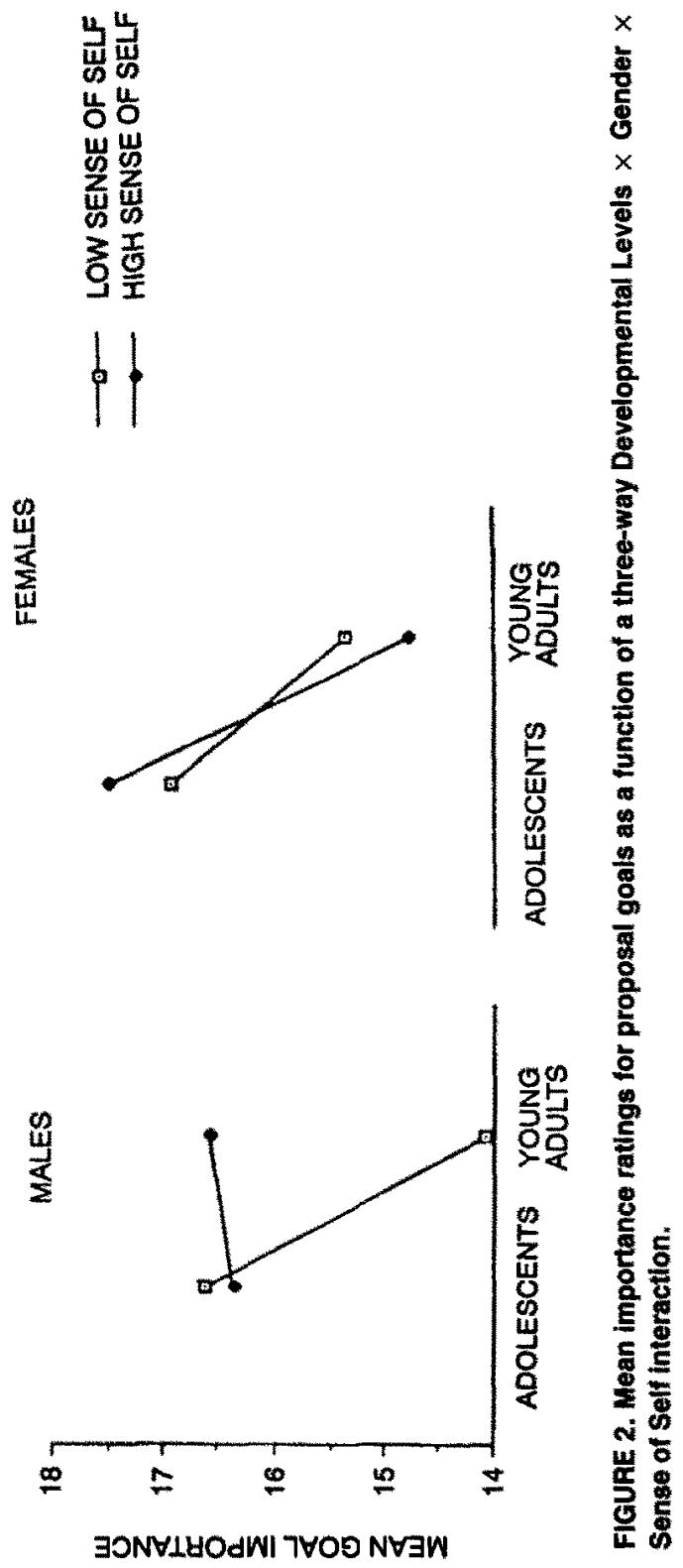




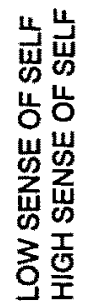

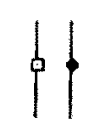

11

䙚
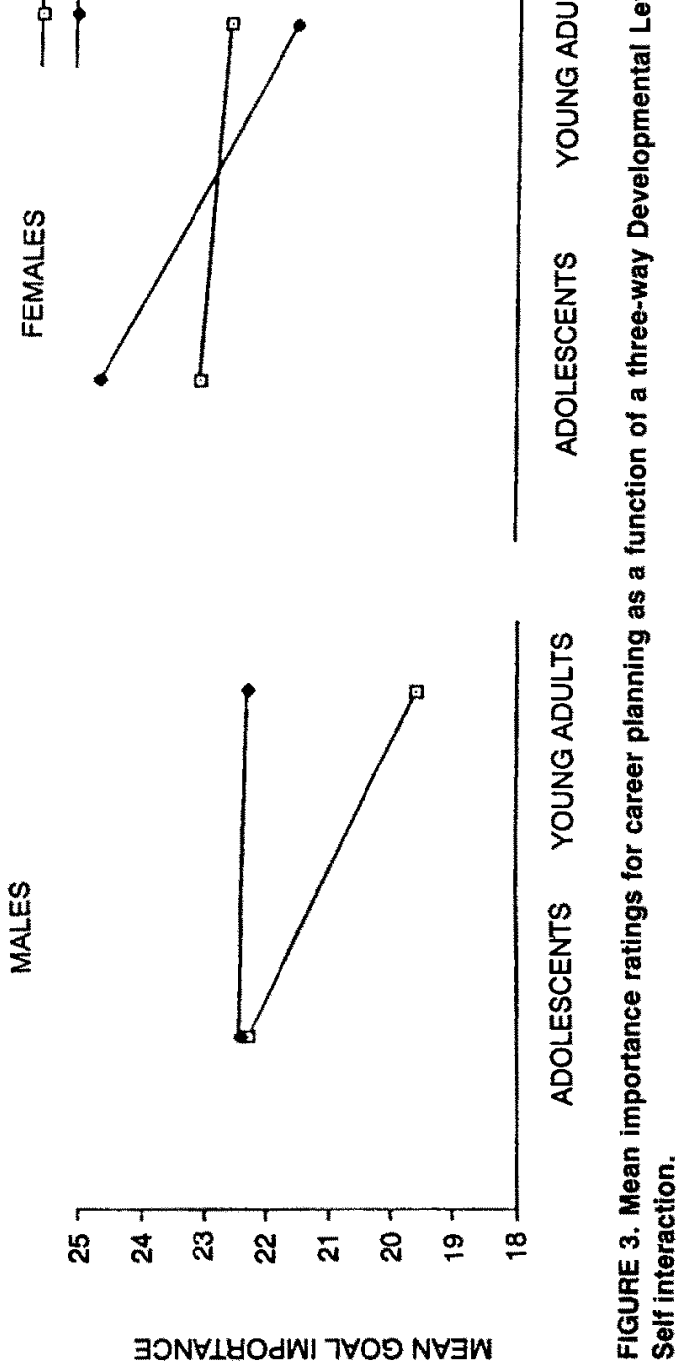
ings for the prosocial and familial goals, whereas career planning and societal goals were emphasized more under the teacher expectation condition. In contrast, peer expectation led to greater emphasis on the positive experiences, whereas while societal goals were more valued under the self-expectation condition. An important feature of these findings is that self-expectation was not distinct from the expectations held by the significant others. Rather, it resembled to the parental expectations very closely and shared considerable similarity with the expectations of teachers. This trend seems to reflect the emphasis on culturally rooted practices and modes of parent-child interactions that shape the construal of goals and values. In the Indian context, several studies have shown (Nandy \& Kakar, 1980; D. Sinha, 1981) that Indian families generally maintain an authoritarian and hierarchical structure that emphasize conformity, obedience, and dependence. The present results demonstrating close correspondence between the patterns of goal importance under perceived self-expectations and expectations of the significant others show the pressure exerted by and the concern on the part of significant others in directing the lives of their kids. This pattern reflects the trend noted by Roland (1988). He observed that Indians are more geared towards the rich interdependencies on hierarchical relationships. Hence, Indian identity evolves around "we," "us," and "ours" rather than "I," "me," or "mine." He considers Indian self as a "relational self." More recently, Markus and Kitayama (1991) noted that in many non-Western cultures such as India and Japan the construal of self is "interdependent" as compared to the construal of self in the West cultural self, which is largely "independent." They have also reported empirical evidence to the effect that Indians consider themselves more similar to significant others than Americans.

The results also showed some interesting developmental changes in the preferences for achievement goals. It was noted that, in general, adolescents perceived these goals as relativcly more important than young adult counterparts. It may be recalled that the younger group of adolescents was from the 10th-grade level and the older group of young adults came from the undergraduate level. These two levels in the Indian educational system represent two crucial and decisive time points in the context of an individual's career. This is particularly important in view of the fact that the scope for occupational choice and job opportunities in the contemporary Indian society is very closely tied to the educational qualifications. The curriculum at the level of 10 th grade is common for all the students, and there is no direct linkage between this level of the educational program and occupational choice. These students are beginning their educational careers and have many choices in terms of pursuing different careers. On the other hand, the undergraduate students were approaching a terminal point of maturity in terms of their 
educational career on account of a choice already made at the level of undergraduate studies. They had limited range of professional options at their disposal. Thus it appears that the younger participants had many options open to them, whereas the range and action possibilities for the older participants were highly restricted. This difference in the range of choices is reflected in the preference of a wide variety of goals by the 10 th graders as opposed to the undergraduate students.

The main effect of sense of self was significant for the goal of positive experience only. This finding is contrary to the results found in the studies done in the Western part of the world where it has emerged to be a very strong variable (Harter, 1982; Maehr \& Braskamp, 1986). However, a critical appreciation of the obtained interaction effects indicates that sense of self and gender interacted with developmental level and expectations to influence the preferences for prosocial and careerplanning goals. These interactions suggest that the age-rclated variations in the perceived importance of goals varied among males and females depending on the level of sense of self. In the case of boys, the agerelated variations occurred among the low-sense-of-self participants, whereas the reverse was true for the females. It was also observed that the difference in goals preferences between low- and high-sense-of-self participants was greater in males at the older age level. In the female participants, however, high sense of self led to more positive goal perception at the younger age level than their older counterparts. These results need some explanation. It seems that with advancing age the prosocial goal and career planning lose their priority for females and are replaced by the goals of marriage and adaptation to a new family. In contrast, the girls at the younger age level experience a relatively greater degree of freedom in choosing their goals and pursuing their interests. Thus, increasing age involves a kind of discontinuity and conflict in the role demands among Indian females. In this case, having a high degree of sense of self would become incompatible with the goals of career and prosocial activities. On the other hand, high sense of self for males continues to be a positive resource across both age levels. Thus, the possibility of role changes during one's life span becomes an important contributor to the pattern of goal preferences. In fact, this differential trend draws our attention to the possible selves representing the salient hopes and fears, which develop in the course of interaction with significant others. As Markus and Nurius (1986) observed, "these possible selves are the direct results of previous social comparisons in which the individual's own thoughts, feelings, characteristics and behaviors have been contrasted to those of salient others" (p. 954).

This position is further supported by the results regarding materialistic, familial, and societal goals. It was found that the gender differences 
diminish with advancing age. A close perusal of the relevant data (see Table 2) reveals that the boys had a rather stable pattern of goal preference, whereas girls gave higher ratings at the younger age level and lower ratings at the older age level. This trend also indicates a major shift in the goal orientation among the female participants. The results also yielded an interesting Developmental Level $\times$ Expectation $\times$ Gender interaction. In this connection, it was noted that although younger female participants viewed these goals as being more importnat across selfand other-expectation conditions, the boys considered it as being less important. In contrast, in the early adulthood stage, both males and females viewed it as being more important under self and peer expectations. This implicates the significance of adopting a life-span perspective while studying achievement goals. The range of concern on the part of teachers and peers shifts with the age of their students. Thus, for older students, the familial goals (e.g., helping siblings, respect for elders, etc.) become of least concern for teachers. These results lend support to Maehr and Braskamp's (1986, p. 69) observation that the experiential world of adults changes over time in significant ways and that perceived options, sense of self, and personal incentives likely shift with these contextual shifts. Therefore, changes in motivation and personal investment patterns are likely to vary with age.

In the light of present results, it seems reasonable to conclude that the situational-contextual approach has the potential to deal effectively with the problems of motivation in diverse cultural and subcultural groups across different settings. It has important implications for changing, managing, and enhancing achievement efforts especially in multicultural contexts. It suggests that goals that reprsent end points with affective properties (Pervin, 1989) are more susceptible to change. However, any attempt to modify goals would have to be organized in the context of the sociocultural milieu, which not only provides the opportunities for the development of these goals but also creates constraints as well as arranges situations for their realization. In terms of a motivational construct, goals emerge to be dynamic in social constructions that exhibit important developmental transitions. The use of goals in predicting, monitoring, and interpreting human behavior has only recently drawn attention of systematic studies. Nuttin (1984) has shown that the goals involve ideational processes and are often reversible in terms of temporal order, which increases the degree of freedom necessary for anticipation, planning, and behavioral regulation. These processes as well as issues of interconnectedness and organization of goals have yet to be sorted out. The future research in this area may focus on the understanding of these functional properties of goals as open systems embedded in the diverse sociocultural contexts. 


\section{REFERENCES}

AGARWAL, R., \& MISRA, G. (1986). A factor analytic study of achievement goals and means. International Journal of Psychology, 21, 717-731.

ANANDLAKSHMY, S. (1975). Socialization for competence. In J. W. Berry \& W. J. Lonner. (Eds), Applied cross-cultural psychology (pp. 202-207). Amsterdam: Swets \& Zeitlinger.

CHEN, C., \& UTTAL, D. H. (1988). Cultural values, parents' beliefs, and childrens' achievement in the United States and China. Human Development, 31, 351-358.

COOPER, W. H. (1983). An achievement motivation nomological network. Journal of Personality and Social Psychology, 44, 841-861.

DEVOS, G. A. (1973). Socialization for achievement: Essays on the cultural psychology of the Japanese. Berkeley: University of California Press.

DOI, K. (1982). A two-dimensional theory of achievement motivation. Japanese Journal of Psychology, 52, 344-450.

DUDA, J. L. (1980). Achievement motivation among Navajo students: A conceptual analysis with preliminary data. Ethos, 8, 316-331.

EWING, M. E. (1981). Achievement orientations and sport behavior of males and females. Unpublished doctoral dissertation, University of Illinois at Urban-Champaign.

FLEMING, J. S., \& COURTNEY, B. E. (1984). The dimensionality of self esteem: II. Hierarchical facet model for revised measurement scale. Journal of Personality and Social Psychology, 46, 404-442.

FYANS, L. J., Jr., SALILI, F., MAEHR, M. L., \& DESAI, K. A. (1983). A cross-cultural exploration into the meaning of achievement. Journal of Personality and Social Psychology, 44, 1000-1013.

GALLIMORE, R. (1974). Affiliation motivation and Hawaiian-American achievement. Journal of Cross-Cultural Psychology, 5, 481-491.

HARTER, S. (1982). The Perceived Competence Scale for children. Child Development, 53, 87-97.

KAKAR, S. (1978). The inner world. New Delhi: Oxford University Press.

KUKLA, A., \& SCHER, H. (1986). Varieties of achievement motivation. Psychological Review, 93, 378-380.

MAEHR, M. L. (1974). Culture and achievement motivation. American Psychologist, 29, 887-896.

MAEHR, M. L. (1978). Socio-cultural origins of achievement motivation. In D. Bar-Tal \& L. Saxe (Eds.), Social psychology of education: Theory and research (pp. 205-227). New York: Wiley.

MAEHR, M. L. (1984). Meaning and motivation: Toward a theory of personal investment. In R. Ames \& C. Ames (Eds.), Research in motivation in education: Student motivation (Vol. 1, pp. 115-144). New York: Academic.

MAEHR, M. L., \& BRASKAMP, L. A. (1986). The motivation factor: A theory of personal investment. Lexington, MA: Lexington Books.

MAEHR, M. L., \& NICHOLLS, J. G. (1980). Culture and achievement motivation: A second look. In N. Warren (Ed.), Studies in cross-cultural psychology (Vol. 3, pp. 221-267). New York: Academic.

MARKUS, H. R., \& KITAYAMA, S. (1991). Culture and the self: Impli- 
cations for cognition, emotion and motivation. Psychological Review, 98, 224-253.

MARKUS, H., \& NURIUS, P. (1986). Possible selves. American Psychologist, 41, 954-969.

MCCLELLAND, D. C. (1961). The achieving society. New Jersey: Van Nostrand.

MEHTA, P., \& MOHTA, N. (1974). Achievement motive research in India. Indian Journal of Psychology, 49, 320-336.

MELIKIAN, L., GINSBERG, A., CUCELOGLU, D. M., \& LYNN, R. (1971). Achievement motivation in Afghanistan, Brazil, Saudi Arabia, and Turkey. Journal of Social Psychology, 83, 183-184.

MILLER, J. G. (1984). Culture and development of everyday social explanation. Journal of Personality and Social Psychology, 46, 961-978.

MISRA, G. (1985). Situational and personal determinants of attributions for achievement outcomes in India. Indian Journal of Community Guidance Service, 2, 1-18.

MISRA, G., \& AGARWAL, R. (1985). The meaning of achievement: Implications for a cross-cultural theory of achievement. In A. R. Lagunes \& Y. H. Poortinga (Eds.), From different perspectives: Studies of behavior across cultures (pp. 250-266). Lisse: Swets and Zeitlinger.

NANDY, A. (1982). A post colonial view of East and West. Alternatives, 8, $25-48$.

NANDY, A., \& KAKAR, S. (1980). Culture and personality. In U. Pareek (Ed.), A survey of research in psychology, 1971-1976. Part-I (pp. 136-167). Bombay: Popular Prakashan.

NICHOLLS, J. G. (Ed.). (1984). The development of achievement motivation. Greenwhich, CT: JAI Press.

NUTTIN, J. (1984). Motivation, planning, and action. Hillsdale, NJ: Erlbaum.

PERVIN, L. A. (Ed.). (1989). Goal concepts in personality and social psychology. Hillsdale, NJ: Erlbaum.

RAMIREZ, M., \& PRICE-WILLIAMS, D. R. (1976). Achievement motivation in children of three ethnic groups in the United States. Journal of CrossCultural Psychology, 7, 49-60.

ROLAND, A. (1988). In search of self in India and Japan. Princeton, NJ: Princeton University Press.

SEYMOUR, S. (1988). Expressions of responsibility among Indian children: Some precursors of adult status and sex roles. Ethos, 16, 355-370.

SHWEDER, R. A., \& BOURNE, E. J. (1984). Does the concept of the person vary cross-culturally? In R. A. Shweder \& R. A. LeVine (Eds.), Culture theory: Essays on mind, self and emotion (pp. 158-199). Cambridge, England: Cambridge University Press.

SINGHAL, R., \& MISRA, G. (1989). Variations in achievement cognitions: The role of ecology, age, and gender. International Journal of Intercultural Relations, 31, 93-107.

SINHA, D. (Ed.). (1981). Socialization of the Indian child. New Delhi: Concept.

SINHA, D. (1988). The family scenario of a developing country and its implications for mental health: The case of India: In P. R. Dason, J. W. Berry, \& N. 
Sartorious (Eds.), Health and cross-cultural psychology: Towards application (pp. 48-70). Newbury Park: Sage.

SINHA, J. B. P. (1982). The Hindu indentity. Dynamic Psychiatry, 19, 148160.

SPENCE, J. T. (1985). Achievement American style: The rewards and costs of individualism. American Psychologist, 40, 1285-1295.

TIWARI, A. N., \& MISRA, G. (1977). A study of achievement motive in relation to prolonged deprivation. Psychologia, 20, 172-179.

TRIPATHI, R. C. (1988). Aligning development to values in India. In D. Sinha \& H. S. R. Kao (Eds.), Social values and development: Asian perspectives (pp. 314-332). New Delhi: Sage.

UPLAONKAR, A. T. (1983). Occupational aspirations of college students. Social Change, 13, 16-26.

WEINER, B. C. (1986). An attributional theory of motivation and emotion. New York: Springer-Verlag.

This paper is being published without benefit of the authors' review of the corrected proof as this was not available at press time. 